Characterization of the TNFR1-SC using 'modified tandem affinity purification' in conjunction with liquid chromatography-mass spectrometry (LC-MS)

Running Head: Characterization of the TNFR1-SC using moTAP and mass spectrometry

Matthias Reichert ${ }^{1}$, Amandeep Bhamra ${ }^{2 \dagger}$, Sebastian Kupka ${ }^{1 \dagger}$, Henning Walczak ${ }^{1, *}$

${ }^{1}$ Centre for Cell Death, Cancer and Inflammation (CCCI), UCL Cancer Institute, University College London, 72 Huntley Street, London, WC1E 6DD, UK

${ }^{2}$ Proteomics Research Core Facility, UCL Cancer Institute, University College London, 72 Huntley Street, London, WC1E 6DD, UK

$\dagger$ These authors contributed equally to the work.

*Correspondence: $\underline{\text { h.walczak@ucl.ac.uk }}$ 


\section{i. Summary/Abstract}

Mass spectrometry enables the unbiased characterization of protein complexes. The success of this approach and the amount of information that can be retrieved are highly dependent on the achieved purity of the protein complex to be analysed. Here we describe a modified tandem affinity purification (moTAP) approach which can be used to isolate the tumour necrosis factor receptor 1 signaling complex for subsequent analysis by liquid chromatography-tandem mass spectrometry. Indeed, this approach can easily be adapted to the isolation of other membrane-bound and intracellular signalling complexes. This methodology allows for a highly sensitive analysis and characterization of complex components, including post-translational modifications and for the identification of novel complex components.

\section{ii. Key Words}

Tandem affinity purification, Immunoprecipitation, Proteomics, Tumor necrosis factor (TNF), TNF receptor 1 signaling complex (TNFR1-SC), liquid chromatography-tandem mass spectrometry (LC$\mathrm{MS} / \mathrm{MS})$

\section{Introduction}

Liquid chromatography-tandem mass spectrometry (LC-MS/MS) is a powerful methodology for the unbiased analysis of complex protein assemblies [1]. This method enables researchers to identify unknown components of protein complexes of interest as well as post-translational modifications thereof. In the protein characterization approach referred to as "bottom-up", the proteins are enzymatically digested by proteases resulting in a mixture of short peptides which are then separated by reverse-phase liquid chromatography before detection in the mass analyzer. Energy is then applied to cleave the peptides specifically along the amide backbone to produce fragment ions. The resulting peptide mass fingerprints (PMFs) are subsequently subjected to in-silico database searching to assign the peptide sequences and corresponding proteins.

To specifically identify and characterize components of a given complex, a sufficient purification process of said complex prior to assessment in the mass analyzer is crucial. Furthermore, insufficient sample purity will result in a higher background noise emanating from peptides originating from more abundant proteins present in the cell lysate. This would suppress signals from far less abundant but specific complex components. A single purification step is often not sufficient to achieve satisfactory purification.

Here, we describe an approach employing a specialized two-step immunoprecipitation, a so-called tandem-affinity-purification, for the purification of the Tumor necrosis factor receptor 1 signaling complex (TNFR1-SC) and the subsequent steps necessary for mass spectrometry analysis. For this, the ligand TNF was fused to a modified version of the original tandem affinity purification (moTAP) tag [2,3]. The moTAP tag consists of a 3x Flag epitope followed by a PreScission cleavage site and a $2 \mathrm{x}$ Strep epitope, enabling a combination of a first high-affinity purification followed by an elution step via a site-specific protease and a second affinity purification step. Using this approach, we were able to identify and characterize novel components of the TNFR1-SC [4,5].

This technique is a sensitive and selective method to purify protein signaling complexes formed under physiological conditions and is not limited to the TNFR1-SC as the tag can be used with any ligand or intracellular protein. 


\section{Materials}

Prepare all solutions and reagents strictly while wearing gloves to avoid protein contamination with keratin or other impurities from contact with skin (see Note 1).

\subsection{Affinity purification}

1. moTAP-TNF. Sequence coding for moTAP-TNF was cloned into $\mathrm{pQE}-30$ and expressed in BL21 E.coli by IPTG induction.

2. Lysis buffer: $30 \mathrm{mM}$ Tris-HCl; pH7.4, $120 \mathrm{mM} \mathrm{NaCl}, 2$ mM EDTA, $2 \mathrm{mM} \mathrm{KCl}, 10 \%$ Glycerol, $1 \%$ lauryl maltoside, $50 \mathrm{mM} \mathrm{NaF}, 5 \mathrm{mM} \mathrm{Na}_{3} \mathrm{VO}_{4}$. Store at $4{ }^{\circ} \mathrm{C}$. (See Note 2)

3. Protease inhibitors: cOmplete ${ }^{\mathrm{TM}}$, EDTA-free Protease Inhibitor Cocktail (Roche)

4. Phosphatase inhibitors: PhosSTOPTM (Sigma-Aldrich)

5. Anti-Flag resin: ANTI-FLAG® M2 Affinity Gel (Sigma-Aldrich)

6. Wash buffer: $30 \mathrm{mM}$ Tris-HCl; pH7.4, $120 \mathrm{mM} \mathrm{NaCl}, 2 \mathrm{mM}$ EDTA, $2 \mathrm{mM} \mathrm{KCl}, 10 \%$ Glycerol, $0.1 \%$ lauryl maltoside, $50 \mathrm{mM} \mathrm{NaF}, 5 \mathrm{mM} \mathrm{Na}_{3} \mathrm{VO}_{4}$. Store at $4{ }^{\circ} \mathrm{C}$.

7. Microcentrifuge tubes, protein LoBind / DNA LoBind (Eppendorf)

8. $3 X$ FLAG ${ }^{\circledR}$ Peptide (Sigma-Aldrich)

9. PreScission Protease (GE Healthcare)

10. Elution Buffer I (Flag peptide + PreScission protease): Wash buffer, $200 \mu \mathrm{g} / \mathrm{ml} 3$ X FLAG® Peptide, $50 \mathrm{U} / \mathrm{mL}$ PreScission protease.

11. Strep-Tactin Superflow Plus (Qiagen)

12. Elution Buffer II (urea): denaturation buffer (100 mM Tris_-HCl), 8_M ürea

\subsection{Protein digestion}

1. Denaturation buffer: $100 \mathrm{mM}$ Tris- $\mathrm{HCl}$ (made up to $\mathrm{pH}$ 8-8.5 using $1 \mathrm{M}$ TEAB (Sigma))

2. Reduction solution: denaturation buffer (100 mM Tris-HCl), $200 \mathrm{mM}$ dithiothreitol (DTT)

3. Alkylation solution: denaturation buffer $(100 \mathrm{mM}$ Tris- $\mathrm{HCl}), 200 \mathrm{mM}$ chloroacetamideic acid (See Note 3)

4. Lysyl endopeptidase/Lys-C (Alpha Laboratories)_Use 1:50 - 1:100 protease to protein ratio

5. Trypsin-EDTA (Invitrogen). Use 1:50 - 1:100 protease to protein ratio

\subsection{C18 clean up}

1. UltraMicro spin columns, Silica C18, 3-30 $\mu \mathrm{g} ; 2-100 \mu \mathrm{L}$ capacity (Part No: SUM SS18V), Nest Group Inc., Southborough, MA

2. $80 \%$ acetonitrile, $0.1 \%$ trifluoroacetic acid (TFA) 

3. $0.1 \%$ TFA
4. $10 \%$ TFA
5. $5 \%$ acetonitrile, $0.1 \%$ TFA
6. $50 \%$ acetonitrile, $0.1 \%$ TFA
7. $0.1 \%$ formic acid 


\section{Methods}

\subsection{Cloning of moTAP tagged Protein of interest}

The different parts of the moTAP-tag were ordered as complementary oligonucleotides and assembled sequentially into the $\mathrm{pE} 30$ plasmid using conventional restriction/ligation techniques. However, it is advisable to have the full tag commercially synthesized as dsDNA. This is offered by many companies and minimizes the potential for cloning mistakes. The amino acid sequence of the moTAP-TNF is shown below and a schematic depiction can be found in Figure 1 (grey sequences represent functional domains as depicted in Figure 1; the sequence in italic represents the start of aa78-233 of TNF).

MRGS HHHHHH GIQ DYKDDDDK A DYKDDDDK AL DYKDDDDK A LEVLFQGP EL WSHPQFEK GGGSGGGSGGGS WSHPQFEK GGGSTSRS RSSSRTP ...

(Figure 1 near here)

\subsection{Cell lysis}

The following instructions are per sample of cells grown to confluency in one $15 \mathrm{~cm}$ dish. Cell lysates must be strictly kept at $4^{\circ} \mathrm{C}$

1. Stimulate cells with $500 \mathrm{ng} / \mathrm{mL}$ of moTAP-TNF.

2. Lyse cells using $1 \mathrm{~mL}$ lysis buffer containing protease inhibitors and phosphatase inhibitors and use cell scraper to transfer cell lysate into an Eppendorf tube. (See Note 4)

3. Centrifuge cell lysate at $13,0009.50016 .200 \times \mathrm{g}$ rpmat $4^{\circ} \mathrm{C}$ for $30 \mathrm{~min}$ to remove insoluble debris.

4. Transfer supernatant into a new Eppendorf tube.

3.3 First purification step (Flag-IP) and elution from anti-Flag resin

1. Add $50 \mu \mathrm{L}$ of pre-washed, undiluted anti-Flag resin to the cell lysate and incubate overnight at $4^{\circ} \mathrm{C}$ while keeping the tube in motion, ideally on a rotating wheel.

2. Centrifuge the anti-Flag resin at $52,, 0002.400 \mathrm{x}$ grpm at $4{ }^{\circ} \mathrm{C}$ for $5 \mathrm{~min}$ and discard supernatant.

3. Wash the resin with $1 \mathrm{~mL}$ of wash buffer containing protease inhibitors and phosphatase inhibitors and repeat centrifugation step. Repeat the washing step two times and in the last step transfer the resin into a protein LoBind Eppendorf tube. (See Note 5)

4. Elute the bound complex from the anti-Flag resin in $400 \mu \mathrm{L}$ of Elution buffer I containing protease inhibitors and phosphatase inhibitors for 6 hours at $4{ }^{\circ} \mathrm{C}$.

5. Centrifuge the anti-Flag resin at $52.000-2.400 \mathrm{x}$ grpm at $4{ }^{\circ} \mathrm{C}$ for $2 \mathrm{~min}$ and transfer eluate into new protein LoBind Eppendorf tube.

6. Repeat elution step as above and incubate overnight at $4{ }^{\circ} \mathrm{C}$ while keeping the tube in motion. 
7. Centrifuge the sample at $5 \underline{2} .4000 \mathrm{x}$ grpm at $4{ }^{\circ} \mathrm{C}$ for $2 \mathrm{~min}$ and transfer supernatant to merge with previously obtained eluate.

\subsection{Second purification step (Strep-IP) and elution from Strep-Tactin resin}

1. Add $60 \mu \mathrm{L}$ of pre-washed, undiluted Strep-Tactin resin to the eluate and incubate overnight at $4^{\circ} \mathrm{C}$ while keeping the tube in motion.

2. Centrifuge the Strep-Tactin resin at $5.000 \mathrm{rpm}$ at $4{ }^{\circ} \mathrm{C}$ for $5 \mathrm{~min}$ and discard supernatant.

3. Wash the resin with $1 \mathrm{~mL}$ of wash buffer containing protease inhibitors and phosphatase inhibitors and repeat centrifugation step. Repeat the washing step two times.

4. Elute bound complex in $120 \mu \mathrm{L}$ of Elution buffer II at $37^{\circ} \mathrm{C}$ for $30 \mathrm{~min}$. (See Note 6 )

5. Centrifuge the sample at $52.4000 \mathrm{x} \mathrm{g} \mathrm{pm}$ at $4{ }^{\circ} \mathrm{C}$ for $2 \mathrm{~min}$ and transfer eluate into new protein LoBind Eppendorf tube.

\subsection{Protein digestion}

1. Add $2 \mu \mathrm{L}$ of reduction solution to the eluate and incubate at $56{ }_{-}^{\circ} \mathrm{C}$ for $25 \mathrm{~min}$. Afterwards, let the sample cool down to room temperature.

2. Add $4 \mu \mathrm{L}$ of alkylation solution to the sample and incubate at room temperature for $25 \mathrm{~min}$, avoiding exposure to light sources.

3. Add $2 \mu \mathrm{L}$ of reduction solution to neutralize the excess of chloroacetamideic acid.

4. Add lysyl endopeptidase in a 1:50 - 1:100 protease to protein ratio and incubate at $37_{-}^{\circ} \mathrm{C}$ for $4 \mathrm{~h}$. Afterwards, let the sample cool down to room temperature. (See Note 7)

5. Dilute the sample 4 times to a concentration of $2 \mathrm{M}$ urea by adding denaturation buffer $(\sim 300 \mu \mathrm{L})$.

6. Add trypsin-EDTA in a 1:50 - 1:100 protease to protein ratio and incubate overnight at $37^{\circ} \mathrm{C}$. Afterwards, let the sample cool down to room temperature.

\subsection{C18-clean up}

For C18-clean up, use a micro spin column with a capacity of 3-30 $\mu \mathrm{g}$ of total protein and 2$100 \mu \mathrm{L}$ of volume.

1. Activate the column by washing it with $200 \mu \mathrm{L}$ of $80 \%$ acetonitrile/ $0.1 \%$ TFA while centrifuging the column at $1.000100 \times \mathrm{g}$ rpm at room temperature for $1 \mathrm{~min}$ for a total of two times.

2. Equilibrate column with $200 \mu \mathrm{L}$ of $0.1 \%$ TFA for a total of three times.

3. Acidify samples to be loaded by adding $50 \mu \mathrm{L}$ of $10 \% \mathrm{TFA}$, which will result in a final concentration of $1 \%$ TFA. Make sure that a $\mathrm{pH}$ of 2.5 is reached.

4. Centrifuge the acidified samples at $139.000 \underline{50016.200 \times \mathrm{g}} \mathrm{rpm}$ at room temperature for 5 $\min$. 
5. Load only the supernatant of the acidified sample on the activated column and centrifuge the column at $1.000100 \times \mathrm{grpm}$ at room temperature for $1 \mathrm{~min}$. Collect the flow through in a clean tube. This step might have to be repeated for the whole supernatant to run through the column.

6. Reload the sample flow-through and repeat the centrifugation step as above to maximize amount of protein binding to the column.

7. Wash the column with $200 \mu \mathrm{L}$ of $5 \%$ acetonitrile/0.1\% TFA to wash away and dilute urea for a total of five times.

8. Place a new tube to collect the eluate and elute the samples with $50 \mu \mathrm{L} 50 \%$ acetonitrile/0.1\% TFA while centrifuging the column at $1.000 \underline{100} \mathrm{xgrpm}$ at room temperature for $1 \mathrm{~min}$ for a total of two times.

9. Concentrate peptides in the eluate to dryness at $23^{\circ} \mathrm{C}$, ideally using speed vacuum centrifugation at $2.0004300 \mathrm{x}$ grpm at room temperature (See Note 8).

10. The lyophilized peptides should be stored at $-80^{\circ} \mathrm{C}$ until ready to run on the LC-MS.

11. Once ready to run on the mass spectrometer, resuspend the peptides in $10 \mu \mathrm{L} 0.1 \%$ formic acid and proceed with analysis. (See Note 9)

(Figure 2 near here)

\subsection{Peptide detection by LC-MS analysis}

Reversed phase chromatography using C18 particles is highly advised for peptide detection.

1. Peptides are concentrated on a precolumn C18 trap.

2. Peptides are then resolved using a C18 analytical column over 60 min with a linear gradient of 96:4 to 50:50 buffer A:B (buffer A: 0.1\% formic acid in water; buffer B: 0.1\% formic acid in acetonitrile) between $200-300 \mathrm{~nL} / \mathrm{min}$.

3. Peptides are then ionized by electrospray ionization (ESI) before being infused into the mass spectrometer. A specific type of data acquisition, known as data-dependent acquisition (DDA) is then triggered.

4. Firstly, the peptides are measured in the mass analyzer with high accuracy and resolution power. MS/MS events are then acquired by selecting the most intense ions to be fragmented by (higher-)collision-induced dissociation (HCD or CID). The precise number of peptide ions sequenced at a given time is determined by the instruments duty cycle.

5. The fragment ions of a particular peptide are then re-analyzed in the mass analyzer to determine its PMF.

6. Once fully acquired, PMF data can be searched against the appropriate databases in-silico using search engines such as Mascot, Sequest and MaxQuant.

\section{Notes}

1. It is of great importance to always wear gloves while handling samples and preparing buffers and solutions. For weighing chemicals, special dedicated instruments should be used that have not been touched with bare hands and should be cleaned before use. Filtered pipette tips 
should be used. This is to prevent contamination of the mass spec samples with keratins or other proteins present in the skin that would cause a contamination of the sample.

2. The detergent Triton must not be used for sample preparation or in any solution that will be subjected to LC-MS analysis. Even small traces of Triton will render samples incompatible for mass spectrometry.

3. If the ubiquitination status of proteins is going to be analyzed, we recommend the use of chloroacetamideic acid over iodoacetamide in the preparation of alkylation solution. This is because alkylation by iodoacetamide can mimic the di-gly remnant which is indicative for protein ubiquitination [6].

4. For optimization purposes and troubleshooting it is highly recommended to take aliquots of samples after each purification step for subsequent analysis by western blot. This should be done at the initial step of lysis, for the supernatants that are being discarded after the respective immunoprecipitations and for the eluates. Furthermore, the affinity resins should be analyzed after the respective elution steps for remainders of the complex of interest that was not successfully eluted. This analysis allows to identify inefficient purification steps that must be optimized.

5. It is recommended to use protein LoBind tubes from the point of elution from the anti-Flag resin onwards. This will minimize the loss of protein which results from unspecific binding to the surface of conventional reaction tubes.

6. The elution from the Strep-Tactin resin using urea is an efficient yet somewhat crude approach. If suspicions of unspecific binding of proteins to the Strep-Tactin resin should arise, it is recommended to use a more specific approach for elution. An alternative is therefore eluting with denaturation buffer and $5 \mathrm{mM}$ biotin at $4{ }^{\circ} \mathrm{C}$ for 24 hours with subsequent protein precipitation (using "2-D Clean-Up Kit" (GE Healthcare) according to manual).

7. The use of LysC in conjunction with trypsin enhances digestion by reducing the tryptic missed cleavage rate. LysC is able to function in harsh conditions such as $8 \mathrm{M}$ urea, which means that it is able to cleave fully denatured proteins efficiently. Trypsin is then introduced to cleave these long peptides after internal arginine residues.

8. Before the final step of the C18-clean up, the peptides contained in the samples should ideally be concentrated to dryness leaving a small droplet at $23-30^{\circ} \mathrm{C}$ using a vacuum centrifuge (e.g. ScanVac). When using a vacuum centrifuge, take precautions not to contaminate samples with dirt and spillage remainders present in the centrifuge, as reaction tubes must stay opened during centrifugation. Clean the centrifuge prior to use if necessary.

9. Thorough resolubilization of peptides is carried out by vortexing followed by sonicating for 10 minutes. Peptides should be left for at least 30 minutes to allow for maximum resolubilization.

\section{Acknowledgements}

We thank P. Draber and L. Spilgies for providing crucial technical advice and L. Spilgies for providing western blot stainings. This work was supported by a Wellcome Trust Senior Investigator Award (096831/Z/11/Z), an ERC Advanced Grant (294880) and a Cancer Research UK programme grant (A17341) awarded to H.W. and a BBSRC CASE studentship (BB/J013129/1) awarded to M.R. This work was also supported by the CRUK-UCL Centre grant (515818) and the Cancer Immunotherapy Accelerator (CITA) Award (525877) from CRUK. 


\section{References}

1. Aebersold R, Mann M (2016) Mass-spectrometric exploration of proteome structure and function. Nature 537 (7620):347-355. doi:10.1038/nature19949

2. Haas TL, Emmerich CH, Gerlach Br, Schmukle AC, Cordier SM, Rieser E, Feltham R, Vince J, Warnken U, Wenger T, Koschny R, Komander D, Silke J, Walczak H (2009) Recruitment of the Linear Ubiquitin Chain Assembly Complex Stabilizes the TNF-R1 Signaling Complex and - tIs Required for TNF-Mediated Gene Induction. Molecular Cell 36 (5):831-844. doi:10.1016/j.molcel.2009.10.013

3. Rigaut G, Shevchenko A, Rutz B, Wilm M, Mann M, Seraphin B (1999) A generic protein purification method for protein complex characterization and proteome exploration. Nat Biotechnol 17 (10):10301032. doi:10.1038/13732

4. Draber P, Kupka S, Reichert M, Draberova H, Lafont E, de Miguel D, Spilgies L, Surinova S, Taraborrelli L, Hartwig T, Rieser E, Martino L, Rittinger K, Walczak H (2015) LUBAC-Recruited CYLD and A20 Regulate Gene Activation and Cell Death by Exerting Opposing Effects on Linear Ubiquitin in Signaling Complexes. Cell Rep 13 (10):2258-2272. doi:10.1016/j.celrep.2015.11.009

5. Kupka S, De Miguel D, Draber P, Martino L, Surinova S, Rittinger K, Walczak H (2016) SPATA2Mediated Binding of CYLD to HOIP Enables CYLD Recruitment to Signaling Complexes. Cell Rep 16 (9):2271-2280. doi:10.1016/j.celrep.2016.07.086

6. Nielsen ML, Vermeulen M, Bonaldi T, Cox J, Moroder L, Mann M (2008) lodoacetamide-induced artifact mimics ubiquitination in mass spectrometry. Nat Methods 5 (6):459-460. doi:10.1038/nmeth0608-459 


\section{Figure Captions}

Figure 1 Sequence of moTAP-TNF with annotation of different tag and cleavage site regions. $\mathrm{H}=$ His-Tag; $\mathrm{P}=$ PreScission cleavage site; $\mathrm{S}=$ Strep-Tag; L=Linker sequence.

Figure 2 Flow chart of steps described in the protocol. Aliquots of lysate and samples after each purification step were analyzed by western blot with subsequent staining of moTAP-TNF and the representative complex component HOIP.

$\mathrm{IP}=$ Immunoprecipitation; post=Supernatant remaining after respective purification step; StrepT=Strep-Tactin.

Figure 1

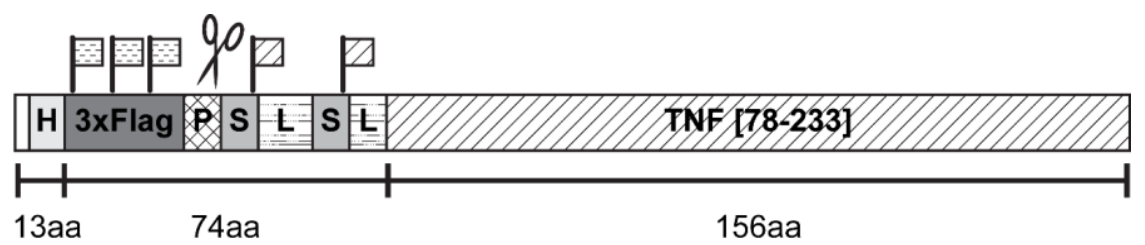

Figure 2

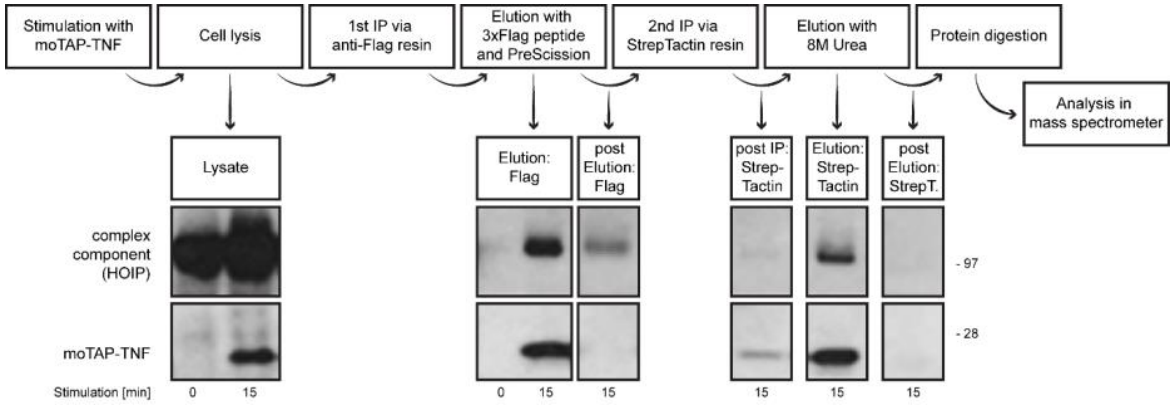

